\title{
Estimating change in the geographical range and population size of Hinde's Babbler Turdoides hindei
}

\author{
PHILIP SHAW, JOHN MUSINA and PATRICK GICHUKI
}

\begin{abstract}
Summary
Hinde's Babbler Turdoides hindei is a globally threatened Kenyan endemic, which during the 1990s, was known from just seven localities. Based mainly on surveys undertaken in 2000-2001, we estimate the species's global population size and compare recent changes in its "extent of occurrence" and "area of occupancy". Historically, Hinde's Babbler has been recorded from c. $4010 \times 10 \mathrm{~km}$ squares; 27 pre-1980 and 19 subsequently, suggesting that its area of occupancy has declined by about 30\%. In contrast, its extent of occurrence has declined by only $8 \%$, this measure being less sensitive to the balance of gains and losses occurring near the centre of its range. During surveys in 1994 and 2000-2001, 157 groups were located, containing 665 birds, $75 \%$ of which were found at two intensively cultivated sites. Some $97 \%$ of birds were located in, or adjacent to, five Important Bird Areas, but only $8 \%$ were found within legally protected areas. Two extrapolated population estimates are presented, based on the number of birds likely to have been missed at survey sites, and the species' area of occupancy. These suggest that the global population of Hinde's Babbler is likely to fall within the range of $1,500-5,600$ birds.
\end{abstract}

\section{Introduction}

Threat status is determined largely from current geographical range and population size, and from the way in which these measures have changed over the past few decades or generations (Collar et al. 1994). To accommodate variation in data quality, two measures of range size have been incorporated into the current IUCN threat criteria: "extent of occurrence" and "area of occupancy" (IUCN 1996, BirdLife International 2000). Extent of occurrence is the area contained within a boundary encompassing sites at which the species is known or inferred to occur (Gaston 1991). Since the species' distribution within this boundary is often patchy, this measure is likely to overestimate geographical range size. Area of occupancy is the total area occupied by the species; the sum of all of the patches in which it does actually occur. Approximations in common use include the number of occupied sites (Gaston and Lawton 1988), the combined area of apparently suitable habitat (Stattersfield et al. 1998) and the number of occupied grid cells (e.g. Gibbons et al. 1993).

At progressively finer scales, grid cell counts provide a useful surrogate for area of occupancy, but may not be practical in the case of widely dispersed species in areas with little ornithological coverage. Habitat mapping may also 
prove impractical for species dependent on ubiquitous, highly fragmented vegetation types. One such is Hinde's Babbler Turdoides hindei, a globally Vulnerable, Kenyan endemic (BirdLife International 2000) associated with riverine scrub and Lantana thickets, often within a mosaic of crops and other managed habitats (Njoroge et al. 1998).

During 1990-2001 Hinde's Babblers were recorded from just seven locations, within an area spanning $207 \mathrm{~km}$ by $108 \mathrm{~km}$, and at an altitude range of c. 7001,580 m (Shaw et al. 2002). In common with many other widely dispersed species, survey coverage has been intermittent, incomplete and therefore difficult to interpret. In this paper we contrast changes in the known extent of occurrence and area of occupancy of Hinde's Babbler, and examine methods for estimating the species' global range and population size.

\section{Methods}

Range size

A thorough review of pre-1980 records of Hinde's Babbler was presented in Plumb (1979). Additional information was extracted from Lewis (1983, 1984), Lewis and Pomeroy (1989), Turner (1992), Shaw (1996), Bennun and Njoroge (1999), Burrell (1999), Mallalieu (1999), Maina and Eshiamwata (2000), Njoroge and Bennun (2000) and from unpublished data held by the National Museums of Kenya.

During June-July 2000 and 2001, surveys were conducted at six locations: Kianyaga $\left(37^{\circ} 21^{\prime} \mathrm{E}, \mathrm{o}^{\circ} 3 \mathrm{o}^{\prime} \mathrm{S}\right)$, Mukurweini ( $\left.37^{\circ} \mathrm{O}^{\prime} \mathrm{E}, \mathrm{o}^{\circ} 33^{\prime} \mathrm{S}\right)$, Machakos ( $\left.37^{\circ} 15^{\prime} \mathrm{E}, 1^{\circ} 3 \mathrm{o}^{\prime} \mathrm{S}\right)$, Mwea National Reserve $\left(37^{\circ} 37^{\prime} \mathrm{E}, \mathrm{O}^{\circ} 5 \mathrm{O}^{\prime} \mathrm{S}\right)$, Kitui $\left(38^{\circ} \mathrm{O} 2^{\prime} \mathrm{E}, 1^{\circ} 25^{\prime} \mathrm{S}\right)$ and on the NW border of Meru National Park $\left(38^{\circ} \mathrm{O}^{\prime} \mathrm{E}, \mathrm{O}^{\circ} 12^{\prime} \mathrm{N}\right)$, referred to here as "Meru". The first three of these had also been surveyed in 1994 (Njoroge and Bennun 2000). Surveys during 2000-2001 were timed to coincide with the end of the long rains, when the Hinde's Babbler population is likely to peak (Shaw et al. 2002).

Changes in extent of occurrence were estimated by measuring the area encompassed by a minimum convex polygon drawn around sites occupied during two time periods. For convenience, the first of these spanned 1900-1979; the period reviewed by Plumb (1979). The second period spanned 1980-2001. Area of occupancy was estimated from the number of $10 \times 10 \mathrm{~km}$ grid cells (hectads) occupied in each period. This was compared with change in the number of occupied quarter-square degrees (QSDs) between the period up to 1984 (Lewis and Pomeroy 1989) and 1985-2001. Each QSD covers approximately $55 \times 55 \mathrm{~km}$.

\section{Population size}

Hinde's Babblers are group-living, territorial, cooperative breeders (Njoroge and Mutinda 1996) and respond vigorously to tape-recordings of their calls (playback). They are strongly associated with vegetation bordering streams and rivers, which, at some sites, flow through steep-sided valleys. Playback was used at fixed intervals along transects, most of which followed watercourses. This approach maximized the amount of time spent searching the species' preferred habitat and the number of individuals located, thus providing an indication of breeding output as well as density (Shaw et al. 2001). Although playback also 
helped raise the sample size, its use precluded the application of survey methods based on measuring detection distance (e.g. distance sampling; Buckland et al. 1993), and hence the estimation of confidence limits around abundance figures.

Transects were mapped using a Garmin 12 Global Positioning System (GPS). Readings were taken at the start and end points, at (paced) intervals of $250 \mathrm{~m}$, and near to each babbler group detected. A tape-recording of Hinde's Babbler calls was played for 1-2 minutes at intervals of $50 \mathrm{~m}$, ensuring that each transect was sampled independently of any variation in habitat "quality". Each group was observed for at least 10-15 minutes, providing sufficient time for stragglers to arrive. Some $114 \mathrm{~km}$ of watercourse and track were surveyed on foot at least once, and $17 \mathrm{~km}$ surveyed in both seasons. Playback was used at an additional 170 locations, mainly in, and adjacent to, Meru National Park (N.P.) and Mwea National Reserve (N.R.).

Surveys were conducted between o7hoo and 19hoo, there being no significant diurnal variation in the ratio of survey effort to detection rate during three consecutive time periods $\left(\chi_{2}^{2}=3.03 ; P=0.22\right)$. A similar lack of diurnal variation in detection rate was evident in surveys of two congeners: Bare-cheeked Babbler $T$. gymnogenys and Northern Pied Babbler T. hypoleucus (Shaw and Shewry 2000, Shaw et al. 2001).

Three estimates of population size were made, as follows.

1. The number of birds counted during the three surveys (1994, 2000 and 2001) was summed, yielding a composite minimum population estimate. Double counting was minimized by incorporating only the most recent count from those areas surveyed more than once.

2. The length of unsurveyed watercourse at each site was multiplied by the mean linear density of birds at that site, yielding an estimate of the number of additional birds present. The same calculation was made for unsurveyed watercourses around each site, i.e. within $1 \mathrm{~km}$ of occupied watercourses. These figures were then added to the minimum population estimate, yielding an extrapolated population estimate for each of the six survey sites.

3. The number of birds present in each hectad occupied during 1980-2001 was estimated from the population density recorded at survey sites in, or adjacent to, the hectad. Population estimates for all occupied hectads were then summed, yielding an estimate for the species' entire known range.

\section{Results}

\section{Distribution}

Plumb (1979) compared the distribution of Hinde's Babbler records during 19001971 and 1972-1979. Numerically, pre-1972 records were equally divided between those clustered around the upper Tana River and its tributaries, and those arising at a few, outlying sites (Figure 1a). During 1972-1979, sites from which Hinde's Babblers were reported increased substantially in number but contracted in range, there being no reports from the outlying areas. This change in distribution largely reflects the level of effort focused on the area between Embu and Thika, surveyed by P.E. Beverly in 1976-1977 (Plumb 1979). Nonethe- 
(a)

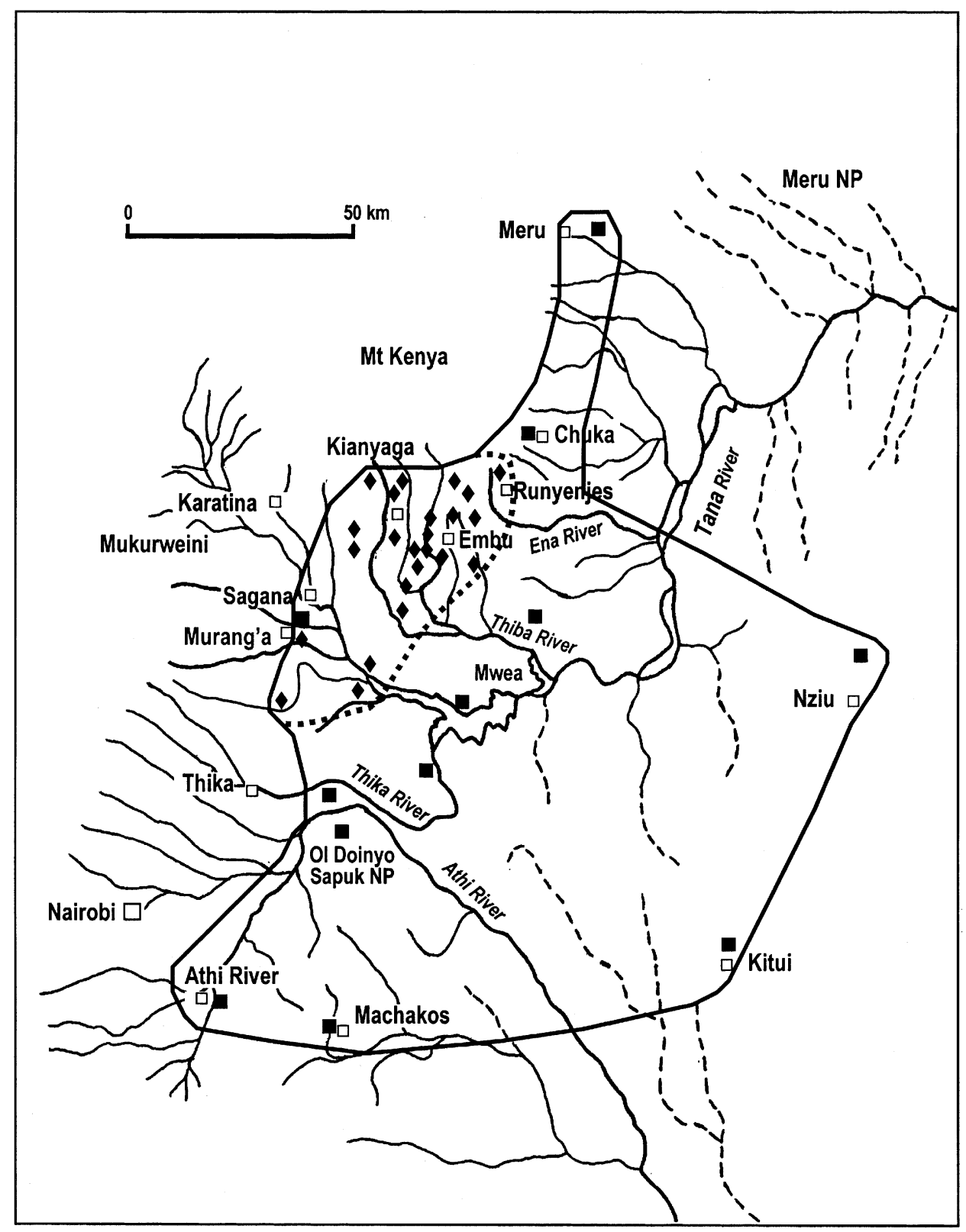

Figure 1a,b. Changes in the known range size of Hinde's Babbler. (a) 1900-1979, re-plotted from Plumb (1979). $\square, 1900-1971 ; \diamond, 1972-1979 ; \square$, town or city. Solid line, outer limits during 1900-1979; dotted line, approximate area in which considered "fairly common" in 1972-1979. (b) 1980-2001, derived mainly from surveys in 1994, 2000 and 2001. $\square$, 19801989 only; , 1990-2001. 
(b)

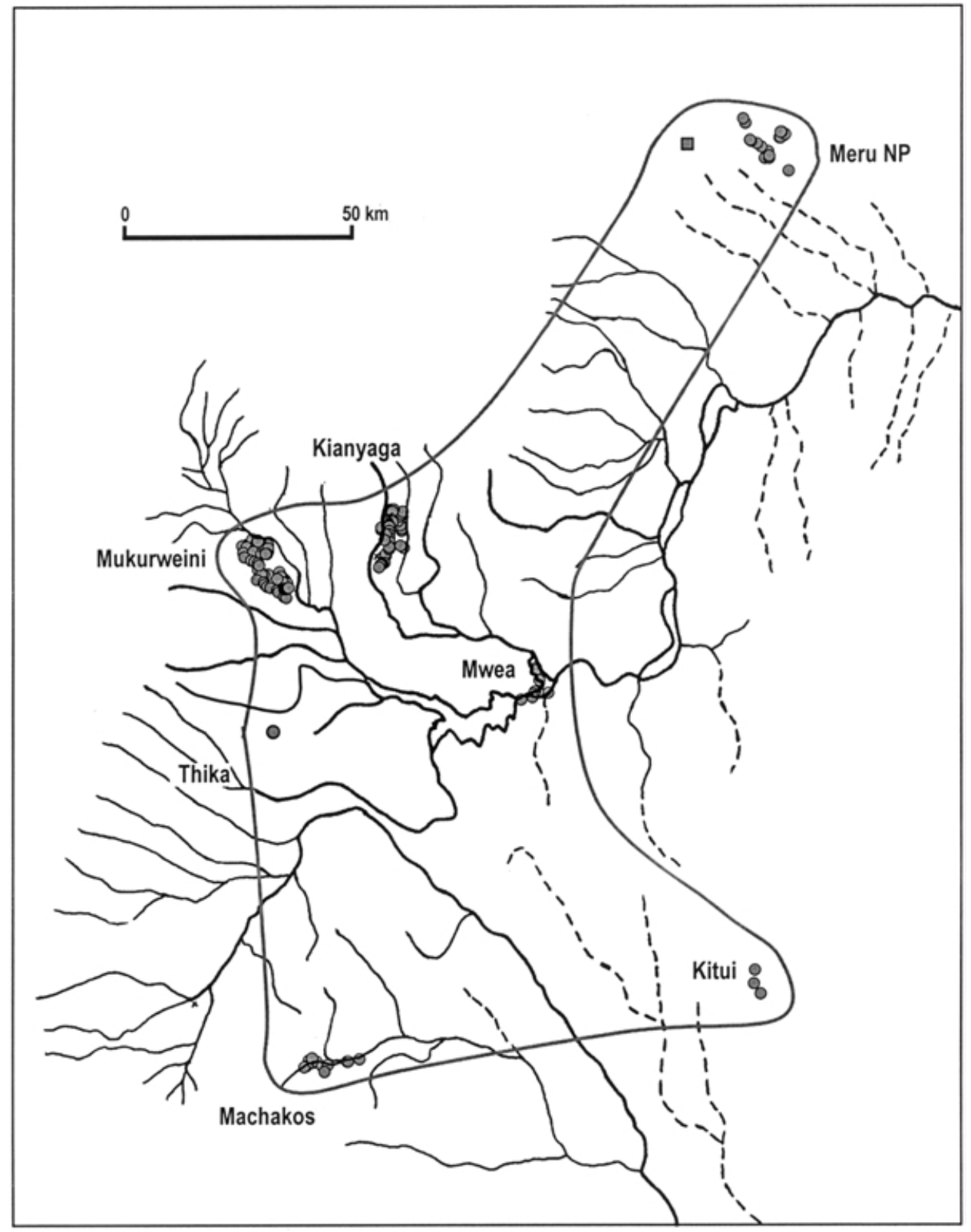


less, attempts to relocate the species at Ol Doinyo Sapuk N.P. and Thika proved unsuccessful, suggesting that its disappearance from some sites was genuine.

During 1980-1999 Hinde's Babblers were rediscovered at Machakos (Lewis 1984), Thika (Mallalieu 1999), Kitui, and at two locations in Meru District: Maua (Lewis and Pomeroy 1989) and Meru N.P. (B. Finch in litt., Maina and Eshiamwata 2000). Their continued presence was thus confirmed at most of the outlying sites, one exception being Nziu River, where the species was last recorded in 1932 and has probably not been searched for since. Groups were also reported from two new localities in the 1990s: Mwea N.R. and Mukurweini Valleys, the latter representing a slight westward extension to its known range (Figure $1 b$ ).

\section{Extent of occurrence}

Plumb (1979) estimated the species' extent of occurrence at $17,500 \mathrm{~km}^{2}$ during 1900-1971, but by 1979 considered it to be "fairly common" only within an area of about $1,050 \mathrm{~km}^{2}$. Plumb's pre-1980 records and range boundary were replotted and measured by counting the number of hectads encompassed (Fig. 1a). This yielded an estimated extent of occurrence of $15,000 \mathrm{~km}^{2}$ pre-1980; slightly lower than that reported by Plumb (1979). By 1980-2001, although the distribution of records had changed markedly (Figure $1 \mathrm{~b}$ ), the species' extent of occurrence had declined by only $8 \%$, to $13,800 \mathrm{~km}^{2}$. The net change in extent of occurrence therefore appears to have been much less severe than indicated by the data available to Plumb (1979).

\section{Area of occupancy}

Strictly defined, the recent area of occupancy of Hinde's Babbler is equal to the sum of the areas of the seven sites from which it was recorded during 1994-2001. Such a figure is likely to substantially underestimate the true area of occupancy, however, given the extent of apparently suitable, unsurveyed land separating known sites. Conversely, the polygon shown in Figure $1 \mathrm{~b}$ may overestimate the species' current range, since it encompasses areas in which conditions are probably no longer suitable, and sites from which Hinde's Babblers appear to have been extirpated. The number of grid cells occupied was therefore considered likely to provide a more accurate measure of range-size, and hence of range-size change between the two time periods.

Hinde's Babblers were recorded in 10 Kenya Bird Atlas QSDs during 19001984 (Lewis and Pomeroy 1989), but in only six QSDs during 1984-2001, suggesting that its range had contracted by about $40 \%$. Similar changes were evident in the number of hectads occupied. During 1900-1979, Hinde's Babblers were recorded from 26-27 hectads, the exact figure depending on the location of sighting(s) made in Meru District in 1944 (Figure 2). Only 19 hectads were known to be occupied during 1980-2001, suggesting a range contraction of $27-30 \%$ (Table 1).

Population size

The surveys of 1994, 2000 and 2001 yielded a composite total of 665 birds in 157 groups (Table 2). These figures incorporate only the most recent counts from 


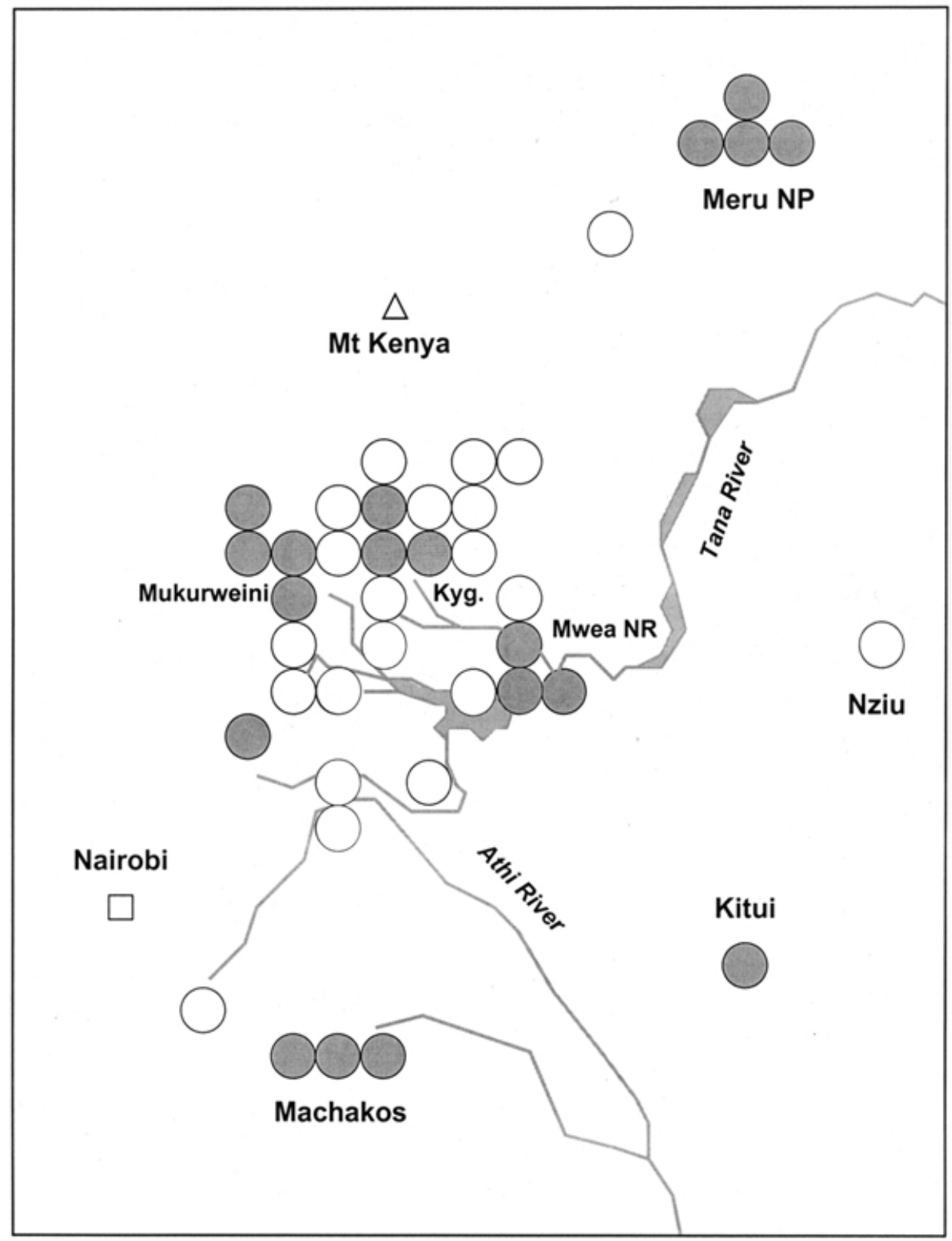

Figure 2. Hectads (10×10 km squares) from which Hinde's Babblers have been recorded. $\bigcirc$, present in 1900-1979 only; 0 , present at least in 1980-2001; $\square$, town or city.

areas surveyed in more than one year. About half of all birds were found at Mukurweini, and a further $24 \%$ were located at Kianyaga. In combination with Mwea N.R., these "core" populations accounted for $77 \%$ of the birds found in recent years. The more peripheral, possibly isolated populations at Kitui, Machakos and Meru each held 2-9\% of the known population. 
Table 1. Changes in the extent of occurrence and area of occupancy of Hinde's Babbler during 19002001.

\begin{tabular}{|c|c|c|c|c|c|c|c|}
\hline \multicolumn{4}{|c|}{ Extent of occurrence } & \multicolumn{4}{|c|}{ Area of occupancy } \\
\hline \multicolumn{2}{|c|}{ Plumb (1979) } & \multicolumn{2}{|c|}{ This study } & \multicolumn{2}{|c|}{$\begin{array}{c}\text { Lewis and Pomeroy } \\
\text { (1989), this study }\end{array}$} & \multicolumn{2}{|c|}{ This study } \\
\hline $1900-1971$ & $17,500 \mathrm{~km}^{2}$ & 1900-1979 & $15,000 \mathrm{~km}^{2}$ & $1900-1984$ & $10 \mathrm{QSD}$ & $1900-1979$ & 27 hectads \\
\hline \multirow[t]{2}{*}{$1972-1979$} & $1,050 \mathrm{~km}^{2}$ & & & & & & \\
\hline & & $1980-2001$ & $13,800 \mathrm{~km}^{2}$ & $1985-2001$ & 6 QSD & $1980-2001$ & 19 hectads \\
\hline$\%$ change & $\mathrm{N} / \mathrm{A}^{\mathrm{a}}$ & & $-8 \%$ & & $-40 \%$ & & $-30 \%$ \\
\hline
\end{tabular}

a The figure for 1972-1979 shows the area in which the species was considered "fairly common" and is therefore not directly comparable with that for 1900-1971.

QSD, quarter-square degrees.

Table 2. Population estimates for six Hinde's Babbler sites surveyed during 1994-2001. The most recent count is given for each site, followed by counts from parts of the site surveyed only in previous years. Counts for 1994 were extracted from Njoroge and Bennun (2000).

\begin{tabular}{|c|c|c|c|c|c|c|c|}
\hline Survey & Kitui & Machakos & $\begin{array}{l}\text { Mwea } \\
\text { N.R. }\end{array}$ & Mukurweini & Kianyaga & Meru & Total \\
\hline 2001 & 16 & 43 & - & 148 & 23 & $70^{\mathrm{a}}$ & 300 \\
\hline $\begin{array}{l}\text { Additional areas } \\
\text { surveyed in } 2000\end{array}$ & - & 7 & 35 & 100 & 60 & - & 202 \\
\hline $\begin{array}{l}\text { Areas surveyed } \\
\text { only in } 1994\end{array}$ & - & 9 & - & 81 & 73 & - & 163 \\
\hline $\begin{array}{l}\text { Minimum } \\
\text { population } \\
\text { estimate }\end{array}$ & 16 & 59 & 35 & 329 & 156 & 70 & 665 \\
\hline $\begin{array}{l}\text { Extrapolated } \\
\text { estimate within } \\
\text { sites }^{\text {b }}\end{array}$ & 52 & 87 & 116 & 717 & 310 & 208 & 1,490 \\
\hline
\end{tabular}

a Only 21 Hinde's Babblers were found inside the National Park.

${ }^{\mathrm{b}}$ See text for details.

Some 413 birds (62\% of the known population) were located within five Important Bird Areas (IBAs) (Kianyaga Valleys, Mukurweini Valleys, Machakos Valleys, Meru N.P. and Mwea N.R.; Bennun and Njoroge 1999). A further $35 \%$ of the known population occurred in land adjacent to IBAs, and could easily be included through small or moderate boundary adjustments. Only 56 birds (8\% of the known population) were found within the two protected areas surveyed: Mwea N.R. and Meru N.P. Thus, even if Hinde's Babblers were to be re-found within Ol Doinyo Sapuk N.P., at which they were last recorded in 1970, the proportion of birds located within legally protected areas would be likely to remain low.

The minimum population estimate is therefore 665 birds. Unsurveyed watercourses within and immediately adjacent to each site were generally similar to those surveyed, in terms of vegetation cover. They were therefore considered likely to support birds at a similar density, yielding an extrapolated population estimate of 1,490 birds in 364 groups at these sites (Table 2). Since parts of the 
intervening area hold suitable habitat, but are rarely visited by ornithologists, this extrapolation is also likely to underestimate the species' true population size. The mean population density recorded at each survey site was therefore used to estimate the population size within the 19 hectads occupied during 1980-2001 (Figure 2). This approach yielded a global population estimate of 5,624 birds in 1,379 groups.

\section{Population changes}

Some $36.5 \mathrm{~km}$ of watercourse surveyed by P. Njoroge at Machakos and Kianyaga in 1994 were re-surveyed during 2000, providing an indication of population change at these sites. Since both surveys were conducted towards the end of the long rains, and used similar methods, abundance estimates are likely to be broadly comparable. The number of birds detected in re-surveyed areas at Kianyaga had declined by $12 \%$, from 58 birds ( 13 groups) to 51 ( 15 groups). At Machakos, the population had increased by $33 \%$, from 30 to 40 birds, while group number had remained stable, at nine. The 91 birds detected during 2000 thus represented a $3 \%$ increase over 1994, suggesting that the combined population of these two areas may have remained relatively stable.

\section{Discussion}

The most parsimonious estimates of range and population size are, respectively, the sum of the areas occupied and the number of birds counted. Where observer coverage is poor, however, such measures may substantially underestimate the true range and population size. Some form of extrapolation is then required, based on a knowledge of the species' ecological requirements, and of the areas in which these are likely to be met.

\section{Range and distribution}

Between 1900-1979 and 1980-2001 the distribution of Hinde's Babbler records expanded in the north and west, while appearing to contract in the east (Figure 1), yielding an estimated $8 \%$ reduction in the species' extent of occurrence. As a means of expressing range size, this measure is relatively insensitive to losses from core sites, but strongly influenced by the quality of data available from outlying sites. If the Nziu population were to be rediscovered, for example, the extent of occurrence would increase by about $20 \%$.

The minimum convex boundary (Figure $\mathrm{rb}$ ) is likely to prove misleading, in several respects. First, it appears unnaturally stretched to accommodate the Meru population, thus forming a narrow corridor largely devoid of Hinde's Babbler records. Also, large sections of the Tana River have been excluded, although this may once have formed a dispersal route linking Meru with Mt Kenya, and may still retain Hinde's Babbler populations. One way of refining Figure $1 b$ would be to exclude areas containing unsuitable habitat, or which lie outside of the species' altitude or rainfall range (e.g. Stattersfield et al. 1998). Its habitat requirements, however, do not appear sufficiently distinctive to enable this approach to be applied with confidence. Moreover, in the course of this survey, Hinde's Babblers 
were recorded down to $700 \mathrm{~m}$ (in Meru N.P.), extending their known altitude range (previously 915-1,700 m; Plumb 1979), and hence expanding their potential geographical range.

An alternative interpretation is that the species' range is now divided into at least three discrete blocks; in the vicinity of Meru N.P., the upper Tana River, and Athi River. This interpretation is partly supported by a lack of historical records linking the Meru population with that at Chuka (c. $80 \mathrm{~km} \mathrm{SW})$, where birds were last seen in 1944. The nearest known population is now $120 \mathrm{~km} \mathrm{SW}$, at Kianyaga. Also, birds seen at Meru in 2001 were highly distinctive in terms of wing and tail colour, suggesting that this population may have been isolated for some considerable time (Shaw et al. 2002).

Populations at Mukurweini, Kianyaga, Mwea and Thika appear to form the core of the species' range. Their proximity to one another, the large size of the Mukurweini and Kianyaga populations, and the existence of shared watercourses, suggest that dispersal between these sites may still be possible. In contrast, the lack of recent records from Ol Doinyo Sapuk N.P. and Athi River suggest that the Machakos and Kitui populations have become isolated from this core area, and from each other.

Changes in the number of hectads occupied since 1980 suggest a $30 \%$ decline in the area of occupancy, from c. 27 to 19 hectads. It is possible, however, that the magnitude of the decline is greater than this. Several other Turdoides species show low dispersal rates and high levels of site fidelity (Gaston 1978a,b, Zahavi 1990, Monadjem et al. 1995), suggesting that Hinde's Babbler sites first noted during 1980-2001 may have been occupied for some time prior to their discovery. If all 40 hectads from which Hinde's Babblers have been recorded were occupied prior to 1980 , the 19 hectads occupied post-1980 would indicate a $52 \%$ decline. It therefore appears that the species' area of occupancy has declined by about $30-52 \%$ since the mid-1900s.

\section{Population size}

Njoroge and Bennun (2000) estimated that the global population of Hinde's Babbler was about 2,700 birds, based on the mean density encountered during their 1994 survey, multiplied by the area in which Hinde's Babblers were thought by Plumb (1979) to be "fairly common" in the 1970s. The area figure used therefore did not include sites at which the species had since been rediscovered (e.g. Machakos) or newly discovered (Mukurweini), and which formed part of their survey.

In this study, the minimum population estimate (665 birds) was derived from counts made during 1994 and 2000-2001. This is the most parsimonious of the three estimates, since no assumption is made regarding the existence of birds outwith the areas surveyed. A second estimate (c. 1,490 birds), which includes unsurveyed habitat in and around each site, assumes that the density of birds in these areas was the same as that recorded in the areas surveyed. This assumption seems reasonable, since several of the unsurveyed valleys, particularly at Mukurweini, appeared highly suitable for Hinde's Babbler. Conversely, a third population estimate (c. 5,624 birds), based on the recent area of occupancy, probably exceeds the true value, since densities recorded within the six survey sites 
were almost certainly higher than those occurring throughout the rest of its range. Thus, after rounding, the global population of Hinde's Babbler is considered likely to fall within the range of $c$. 1,500-5,600 birds, and probably lies closer to the lower figure.

These findings are consistent with the species' current threat classification (Vulnerable), in terms of population decline, extent of occurrence, area of occupancy and estimated population size. Although recently recorded at seven locations, these appear to comprise three discrete blocks, supporting approximately 78\% (upper Tana River), 11\% (Athi River sites) and 10\% (Meru) of the known population. Their apparent isolation increases the risk of further, local extinctions, and additional survey work is required to assess levels of dispersal (if any) between these populations, to refine estimates of their size, and to determine their likely viability. Specifically, the existence of habitat corridors linking Kianyaga and Mukurweini, Machakos and Kitui, and each of the three blocks, should be investigated. As a priority, more detailed surveys are also required of the Meru population, the southern boundary of the Mukurweini population, Ol Doinyo Sepuk N.P. and Nziu River. In view of the species' dependence on thickets (Njoroge et al. 1998, Shaw et al. 2001, 2002), local farmers should be encouraged to retain or restore adequate thicket cover at all occupied sites, along habitat corridors (e.g. watercourses) linking sites, and in previously occupied areas, facilitating re-colonization. More detailed proposals are currently under development in a draft Species Action Plan.

\section{Acknowledgements}

This study was part-funded through a British Ecological Society award to P.S. (Small Ecological Project Grant No. 1909). The Royal Society for the Protection of Birds (the BirdLife International Partner in the U.K.) kindly contributed to the Kenyan team members' field expenses in 2000. We thank the Kenya Wildlife Service for their assistance, in particular staff at Mwea National Reserve and at Meru National Park. Colleagues at the National Museums of Kenya also assisted, in particular Leon Bennun, who provided both support and encouragement. We also thank Leon Bennun, Ara Monadjem, Peter Njoroge and Mike Shewry for their valuable comments on a draft of this paper. Lazarus Nyamu Kariuki and John Chege provided field assistance at Mukurweini.

\section{References}

Bennun, L. and Njoroge, P. (1999) Important Bird Areas in Kenya. Nairobi: East African Natural History Society.

BirdLife International (200o) Threatened birds of the world. Barcelona and Cambridge, U.K.: Lynx Edicions and BirdLife International.

Buckland, S.T., Anderson, D.R., Burnham, K.P. and Laake, J.L. (1993) Distance sampling: estimating abundance of biological populations. London: Chapman and Hall.

Burrell, J.H. (1999) Birding in ... Embu. Kenya Birds 7(1\&2): 23-28.

Collar, N.J., Crosby, M.J. and Stattersfield, A.J. (1994) Birds to watch 2. The world list of threatened birds. Cambridge, U.K.: BirdLife International (BirdLife Conserv. Series 4).

Gaston, A.J. (1978a) Ecology of the common babbler Turdoides caudatus. Ibis 120: 415-432. 
Gaston, A.J. (1978b) Demography of the jungle babbler Turdoides striatus. J. Anim. Ecol. 47: $845-870$.

Gaston, K.J. (1991) How large is a species' geographic range? Oikos 61(3): 434-437.

Gaston, K. and Lawton, J.H. (1988) Patterns in body size, population dynamics and regional distribution of bracken herbivores. Am. Nat. 132: 662-68o.

Gibbons, D.W., Reid, J.B. and Chapman, R.A. (1993) The new atlas of breeding birds in Britain and Ireland: 1988-1991. London: T. \& A.D. Poyser.

IUCN (1996) 1996 IUCN Red List of threatened animals. Gland, Switzerland: IUCN.

Lewis, A.D. (1983) Old records of some scarce or little-known species from Kenya. Scopus 7: 89-90.

Lewis, A.D. (1984) Hinde's Pied Babbler Turdoides hindei south of Machakos, Kenya. Scopus 8: 48-49.

Lewis, A.D. and Pomeroy, D. (1989) A bird atlas of Kenya. Rotterdam: A.A. Balkema.

Maina, M. and Eshiamwata, G. (2000) Ringing in Kindani, Meru. Kenya Birds 8(1): 9-10.

Mallalieu, M. (1999) Hinde's Babblers and Blue Quail near Thika. Kenya Birds 7(1 \& 2): 6o-61.

Monadjem, A., Owen-Smith, N. and Kemp, A.C. (1995) Aspects of the breeding biology of the Arrowmarked Babbler Turdoides jardineii in South Africa. Ibis 137: 515-518.

Njoroge, P. and Bennun L. (2000) Status and conservation of Hinde's Babbler Turdoides hindei, a threatened species in an agricultural landscape. Ostrich 71 (1 \& 2): 69-72.

Njoroge, P. and Mutinda, D. (1996) Notes on nesting of Hinde's Babbler Turdoides hindei and Northern Pied Babbler T. hypoleucus in Central Kenya. Ostrich 67: 170-172.

Njoroge, P., Bennun, L.A. and Lens, L. (1998) Habitat use by the globally endangered Hinde's Babbler Turdoides hindei and its sympatric relative, the Northern Pied Babbler T. hypoleucus. Bird Conserv. Internatnl. 8: 59-65.

Plumb, W.J. (1979) Observations on Hinde's Babbler Turdoides hindei. Scopus 3(3): 61-67.

Shaw, P. (1996) A search for Hinde's Babbler north of Embu. Kenya Birds 5(1): 34-35.

Shaw, P. and Shewry, M. (2000) Abundance, group size and breeding success of Barecheeked Babblers Turdoides gymnogenys. Ibis 142: 58-64.

Shaw, P., Gichuki, P. and Musina, J. (2002) A survey of Hinde's Babbler Turdoides hindei at five sites, June-July 2001. Research Reports of the Centre for Biodiversity, National Museums of Kenya: Ornithology 42 (2002).

Shaw, P., Musina, J. and Gichuki, P. (2001) Surveys of Hinde's Babbler Turdoides hindei and Northern Pied Babbler T. hypoleucus in four Important Bird Areas. Research Reports of the Centre for Biodiversity, National Museums of Kenya: Ornithology 40 (2001).

Stattersfield, A.J., Crosby, M.J., Long, A.J. and Wege, D.C. (1998) Endemic Bird Areas of the world. Priorities for biodiversity conservation. Cambridge, U.K.: BirdLife International (BirdLife Conserv. Series 7).

Turner, D. (1992) Threatened birds of Kenya 2: Hinde's Babbler. Kenya Birds 1(2): 46-47.

Zahavi, A. (1990) Arabian Babblers: the quest for social status in a cooperative breeder. In: P.B. Stacey and W.D. Koenig, eds. Cooperative breeding in birds: long-term studies of ecology and behavior. Cambridge U.K.: Cambridge University Press.

\section{PHILIP SHAW}

Scottish Natural Heritage, 2 Anderson Place, Edinburgh EH6 5 NP UK.

E-mail: phil.shaw@snh.gov.uk

JOHN MUSINA and PATRICK GICHUKI

National Museums of Kenya, Department of Ornithology, P.O. Box 40658, Nairobi, Kenya. 